\title{
Photocatalytic degradation of rohdamine B by modified zinc oxide catalysts
}

\author{
A.G. Abd-El-Hameed ${ }^{1}$, S.A. El-Hakam ${ }^{2}$, Z.A.El-Samia ${ }^{1}$ \\ ${ }^{1}$ Basic Science Department, Nile Higher Institute for Engineering and Technology, Egypt \\ ${ }^{2}$ Chemistry Department, Faculty of Science, Mansoura University, Egypt
}

\begin{abstract}
Aqueous solutions of organic contaminant like rhodamine B) is photodegraded under ultraviolet visible light using modified $\mathrm{ZnO}$ by MCM-41 as photocatalyst, due to its low costs, use of sunlight, mild reaction conditions, high photochemical reactivity, low environmental toxicity and stability to photocorrosion. $\mathrm{ZnO}$ and MCM-41/ZnO photocatalysts with different percentage of MCM$41 / \mathrm{ZnO}(1 \%, 3 \%, 5 \%$, and $8 \%)$ were prepared by precipitation method. Nanocomposites was synthesized and characterized by X-ray diffraction (XRD).
\end{abstract}

\section{Introduction}

Water treatment can be achieved by physical method such as flocculation and filtration or by biological treatment. These processes are easy and low coast. But not effective in low concentration of organic and inorganic contaminates and usually used at the beginning of the purification process to remove solids from the water [1-5]. Where, Chemical methods had been improved to remove low concentration of contaminates such as photocatalytic degradation of the organic pollutants using semiconductors such as $\mathrm{TiO}_{2}$ and $\mathrm{ZnO}$. Most organic pollutants escape from traditional wastewater treatment but photocatalytic degradation method evolved from 
research works has been considered to overcome many limitations of traditional wastewater treatment process.

Photocatalysis processes are classified homogeneous and heterogeneous system. Visible-lightdriven Heterogeneous photocatalysis is an advanced oxidation processes (AOP) it could successfully solve the problem of the removal of toxic and bio-resistant organic and inorganic compounds from waste water by their total conversion into species that are non-toxic [6-11]. It gives a good chance of offering a technology well suited to the above requirements.

\section{Materials}

All organic and inorganic chemicals used in preparation of catalysts are zinc acetate dihydrate $\mathrm{Zn}\left(\mathrm{CO}_{2} \mathrm{CH}_{3}\right)_{2} \quad\left(\mathrm{H}_{2} \mathrm{O}\right)_{2}$, ethanol $\left(\mathrm{C}_{2} \mathrm{H}_{5} \mathrm{OH}\right)$, sodium hydroxide $(\mathrm{NaOH})$, MCM-41, methylene blue dye and rhodamine B dye . All reagents used in this study were in analytical grade.

\section{Preparation of the catalysts:}

\section{1 preparation of $\mathrm{ZnO}$ nanocatalyst.}

Synthesise of $\mathrm{ZnO}$ nanocrystslline particle was suggested by precipitation method. Where, 2.701g of zinc acetate dehydrate dihydrate $\mathrm{Zn}\left(\mathrm{O}_{2} \mathrm{CCH}_{3}\right)_{2}\left(\mathrm{H}_{2} \mathrm{O}\right)_{2}$ was dissolved in $50 \mathrm{ml}$ ethanol at room temperature until clear solution is obtained, sufficient amount of $\mathrm{NaOH}$ is added drop by drop to reach $\mathrm{pH}(8: 9)$, the formed product was then filtered off and dried in a rotary at $60^{\circ} \mathrm{C}$, the nanocrystalline material was finally obtained by calcination of hydroxide structure at $400{ }^{\circ} \mathrm{C}, 500$ ${ }^{\circ} \mathrm{C}$ and $600{ }^{\circ} \mathrm{C}$ for $2 \mathrm{hr}$.

\subsection{Preparation of MCM-41/ $\mathrm{ZnO}$ nanocatalyst.}

MCM-41 supported on $\mathrm{ZnO}$ by impregnation method. Where, 0.01, 0.03, 0.05 and $0.08 \mathrm{~g}$ calcined MCM-41 dispersed under vigorous stirring into solution contain $2.701 \mathrm{~g}$ of zinc acetate dehydrate dihydrate $\mathrm{Zn}\left(\mathrm{O}_{2} \mathrm{CCH}_{3}\right)_{2}\left(\mathrm{H}_{2} \mathrm{O}\right)_{2}$ was dissolved in 50ml ethanol to obtain $1 \mathrm{wt} . \%$, 3 wt. \% , 5 wt. $\%$ and 8 wt. \%MCM-41, respectively. The stoichiometric amount of $\mathrm{NaOH}$ is added drop by drop with vigorous stirring to reach $\mathrm{pH}(8: 9)$ for $12 \mathrm{hr}$. The formed product was then filtered off and dried in arotary at $60^{\circ} \mathrm{C}$. The catalyst was finally obtained by calcination at $400{ }^{\circ} \mathrm{C}, 500$ ${ }^{\circ} \mathrm{C}$ and $600{ }^{\circ} \mathrm{C}$ for $2 \mathrm{hr}$. the catalyst was given name as (X-MCM-41/ZnO) where $\mathrm{X}(1 \%, 3 \%, 5 \%$ and 8 wt. \%) 


\section{Photocatalytic experiments}

The photocatalytic activity of $\mathrm{ZnO}$ and wt. \%MCM-41/ZnO was studied by the degradation of RB under visible light. Photocatalytic degradation of dyes studies were carried out with $0.05 \mathrm{~g}$ of activated catalyst introduced into $50 \mathrm{ml}$ of RB dye solutions with initial dye concentration $10 \mathrm{mg} / \mathrm{l}$. The degradation equilibrium of RB by the prepared materials was reached after $1 \mathrm{hr}$ of stirring under visible light by using UV/visible mercury lamp (400 watt). The suspensions were filtered by centrifuge. [12] The percentage degradation of dyes was calculated by the following equation.

$$
\begin{aligned}
& \text { Degradation }(\%)=\frac{C o-C e}{C o} \times 100 \\
& \left(C / C_{o}\right)=\frac{C_{t}}{C_{\text {intial }}}
\end{aligned}
$$

where;

$C_{o}$ : is the initial concentration of the dye $(\mathrm{mg} / \mathrm{L})$

$C_{t}$ : is the concentration of dye at any $\mathrm{t}_{\text {minute }}(\mathrm{mg} / \mathrm{L})$.

\section{Result and discussion}

\subsection{X-ray diffraction}

\subsection{X-ray diffraction of zinc oxide catalyst.}

The X-Ray Diffraction patterns were measured for $\mathrm{ZnO}$ prepared by sol gel method. Fig. (1) Shows the XRD patterns of $\mathrm{ZnO}$ calcined at $500{ }^{\circ} \mathrm{C}$. It represents high angle powder XRD patterns of pure $\mathrm{ZnO}$. Pure $\mathrm{ZnO}$ sample exhibit peaks at $2 \theta=31.6,34.2$, 36.3, 47.4, 56.76, 62.9, 68.1 nm. Which are characteristic for $\mathrm{ZnO}$ nanostructures with hexagonal crystal type, and with nanosize 55.0-77.2 nm. This results agree with literature XRD pattern for hexagonal wurtzite $\mathrm{ZnO}$ according to literature [13-15]. These diffraction peaks are in a good agreement with the standard joint Committee on powder diffraction standards the JCPDS (card No.36-1451). 


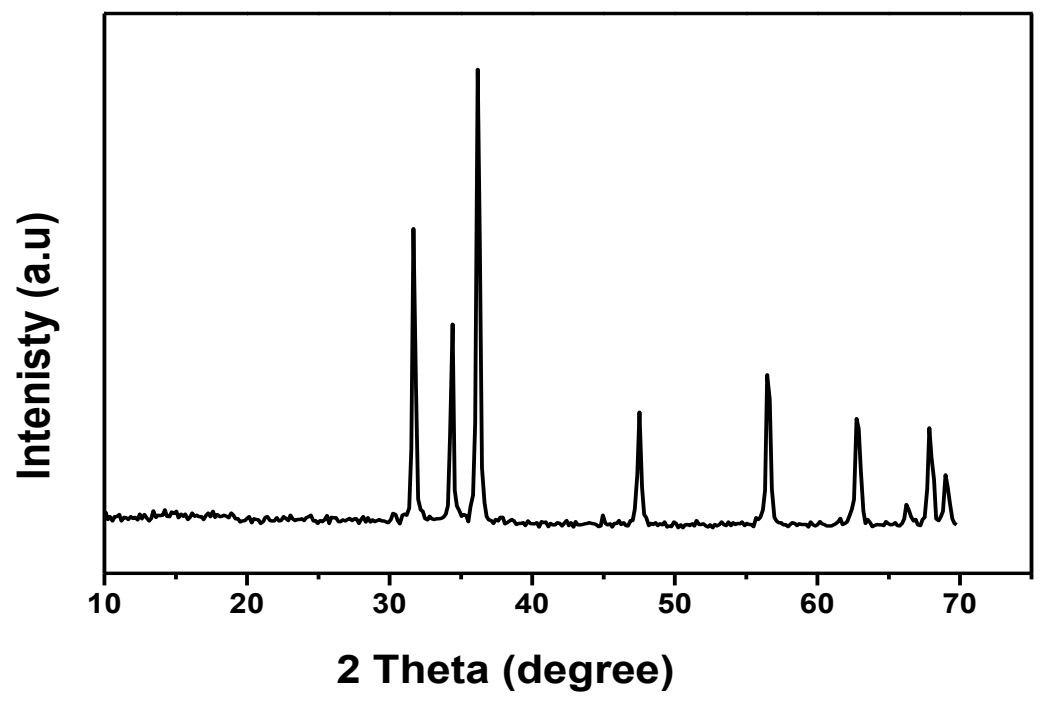

Fig.(1): X-ray diffraction patterns for pure $\mathrm{ZnO}$ calcined at $500{ }^{\circ} \mathrm{C}$. 5.1.2 X-ray diffraction of MCM-41/ ZnO.

The XRD patterns of pure zinc oxide, 1 wt. $\%, 3$ wt. $\%$ and 5 wt. $\% \mathrm{MCM}-41 / \mathrm{ZnO}$ calcined at $500^{\circ} \mathrm{C}$ are shown in fig. (2). the peaks appear at $2 \theta=31.6,34.2,36.3,47.4,56.76,62.9$, $68.1 \mathrm{~nm}$, were confirmed hexagonal structure of MCM-41/ZnO, The products exhibited sharp and narrow peaks at $30-40^{\circ}$ for all samples, [16-21] indicate high degree of crystallinity.

The results indicates that \% MCM-41 supported on $\mathrm{ZnO}$ does not affect the structure of $\mathrm{ZnO}$ crystals, expect only a slight decrease its major $\mathrm{x}$-ray diffraction peak at $2 \theta=31.6,34,2$ and $2 \theta=36.3 \mathrm{~nm}$, which indicate the crystallinity of hexagonal $\mathrm{ZnO}$, peaks intensity decrease by increasing MCM-41 content. the crystallite size of hexagonal $\mathrm{ZnO}$ phase increases with increasing MCM-41 content until $3 \mathrm{wt} . \%$ and then decrease at $5 \mathrm{wt} . \% .3 \mathrm{wt} . \% \mathrm{MCM}-41$ sample was the best nanosize and photodegradation activity. The crystallite size of samples are summarized in table (1)

The degree of crystallinity of the ZnO/MCM-41 samples increased with amount MCM-41 content accordance to nanosize. 


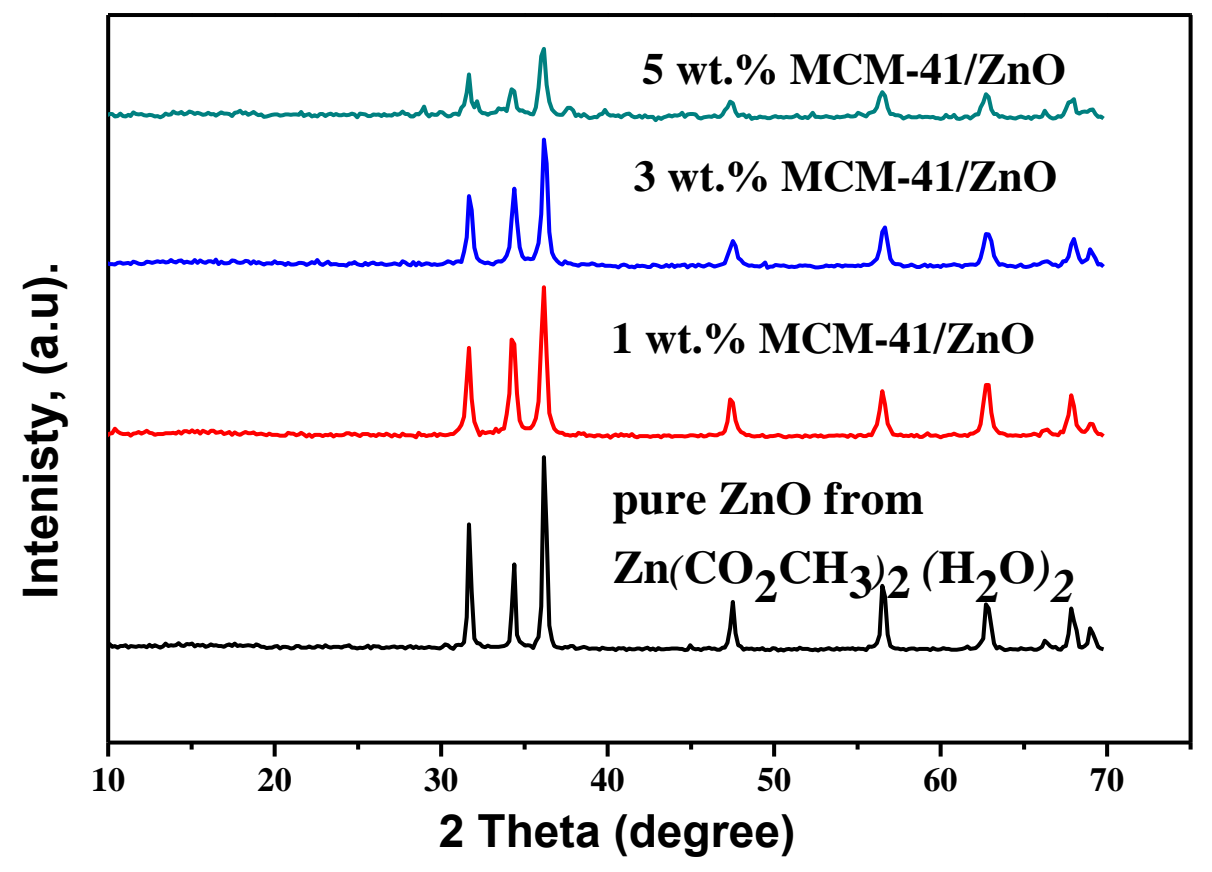

Fig.(2): XRD patterns of $\mathrm{ZnO}, 1 \% \mathrm{MCM} / \mathrm{ZnO}, 3 \% \mathrm{MCM} / \mathrm{ZnO}$ and $5 \% \mathrm{MCM} / \mathrm{ZnO}$.

Table (1): Effect of calcination temperatures on crystallite size of $\mathrm{ZnO}, 1 \% \mathrm{MCM} / \mathrm{ZnO}$, $3 \% \mathrm{MCM} / \mathrm{ZnO}$ and $5 \% \mathrm{MCM} / \mathrm{ZnO}$.

\begin{tabular}{||c||c||}
\hline \multicolumn{1}{|c|}{ Sample name } & Crystallite size L (nm) \\
\hline \hline Pure ZnO from Zn (acetate) & $55-77.2$ \\
\hline \hline 1wt\% MCM-41/ZnO & $23.4-38.4$ \\
\hline 3wt\% MCM-41/ZnO & $19.7-37.6$ \\
\hline \hline 5wt\% MCM-41/ZnO & $22-39.8$ \\
\hline
\end{tabular}

Photocatalytic degradation of rohdamine B by MCM-41/ $\mathrm{ZnO}$ from zinc acetate. 


\subsubsection{Effect of MCM-41 weight percentage of MCM-41/ZnO nanocomposites.}

The photocatalytic degradation of RB dye [22-24] was studied at different time by using $0.05 \mathrm{~g}$ of photocatalyst, and $10 \mathrm{ppm}$ dye solution. Firstly we studied the adsorption activity in dark for 60 minutes, before the study of its photocatalytic activity.[45-48]

The photocatalytic activity of $\mathrm{ZnO}$ samples[25] supported with different amount of MCM-41 were first increasing with MCM-41 content, reaching maximum at 5wt.\% MCM-41/ZnO then decreasing with increasing MCM-41content. Activity decreases at higher MCM-41 contents due to the increased scattering of photons and absorbance through excess MCM-41 in the photosystem. Increasing MCM-41 content can therefore shield the light from reaching the surface of $\mathrm{ZnO}$ nanocatalyst. But suitable amount of MCM-41 doped with $\mathrm{ZnO}$ nanostructure has effects on the surface area of the photocatalyst and the separation of photogenerated electron-hole pairs.

The results indicate that the adsorption activity for $1 \mathrm{wt} . \%, 3 \mathrm{wt} . \%$, and 5 wt. \% MCM$41 / \mathrm{ZnO}$ nanocomposites were insignificant, it did not exceed $10 \%$ adsorption after 60 minutes, while on 8 wt. \% MCM-41/ZnO nanocomposite was $40 \%$ adsorption. We found that the adsorption activity of 1 wt. \%, 3 wt. \%, and 5 wt. \% MCM-41/ZnO nanocomposites showed improvement in photocatalytic activity due to the adsorption of the dye on the surface of the photocatalyts, thus

photocatalytic degradation activity occurs easily. While, 8 wt. \% MCM-41/ZnO nanocomposites has high adsorption activity and the photocatalytic degradation was low. Fig.(3) show the effect of contact time from 0-150 minutes on the photocatalytic degradation efficiency of MB and RB dyes respectively with different loading MCM-41 weight percentage content. Result shows that, the adsorption part in dark after 60 minutes is small due to the low concentration of MCM-41. The most effective content was 3 wt. \% MCM-41 which degraded MB dye after 90 minutes by high percentage reaches to $99.42 \%$, and $\mathrm{RB}$ after 180 minutes by $85.57 \%$. The photocatalytic degradation of two dyes displays quick increase during the first 30 minutes, and then gradually increases during 30 to $60 \mathrm{mins}$, and thereafter the degradation becomes slight. The maximum photocatalytic degradation efficiency of RB is shown in table (3). The experimental data, XRD confirm that the $3 \mathrm{wt}$ \% MCM-41/ZnO nanocomposites was the best photocatalytic activity due to the low nanosize. 


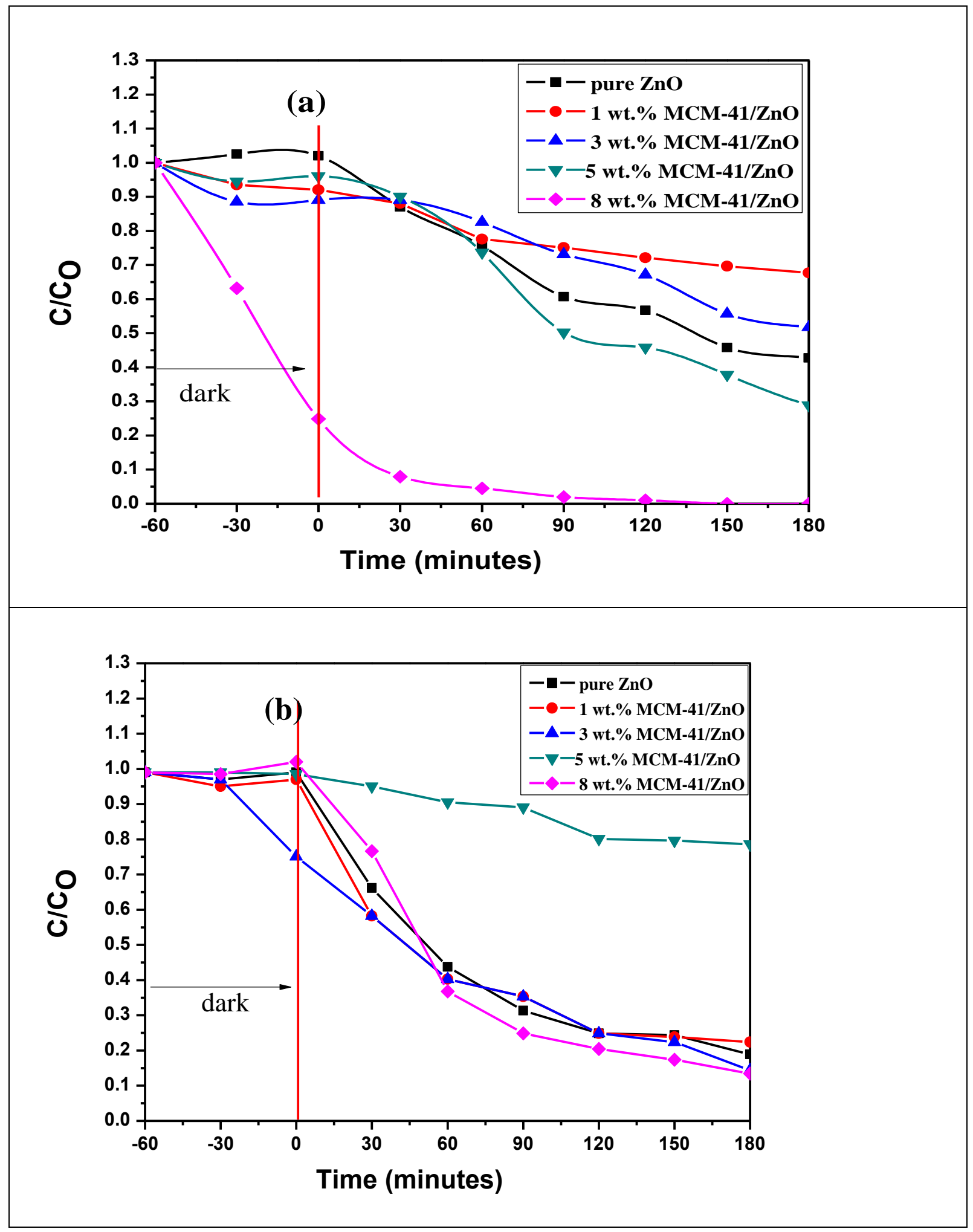




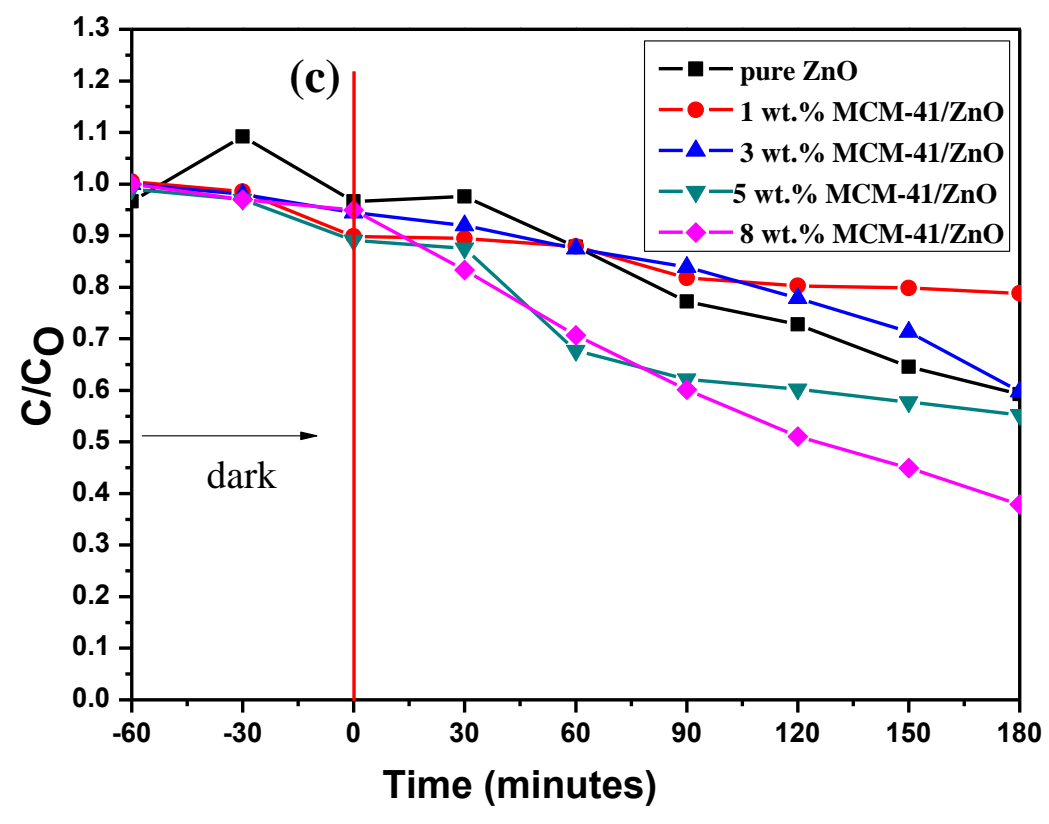

Fig. (3): Effect of contact time on photocatalytic degradation of RB by MCM-41/ ZnO nanocomposites calcined at $(a) 400{ }^{\circ} \mathrm{C}$, (b) $500^{\circ} \mathrm{C}$ and (c) $600{ }^{\circ} \mathrm{C}$

Table (2): The percentage degradation of rhodamine $B$ after 180 mins.

\begin{tabular}{|c|c|c|c|}
\hline \multirow{2}{*}{ The samples } & \multicolumn{3}{|c|}{ Calcination temperatures } \\
\hline & $400^{\circ} \mathrm{C}$ & $500^{\circ} \mathrm{C}$ & $600{ }^{\circ} \mathrm{C}$ \\
\hline Pure $\mathrm{ZnO}$ & 62.6 & 81.02 & 40.7 \\
\hline $\begin{array}{c}1 \% \\
\mathrm{MCM}-41 / \mathrm{ZnO}\end{array}$ & 23.2 & 79.1 & 21.2 \\
\hline $\begin{array}{c}3 \% \\
\mathrm{MCM}-41 / \mathrm{ZnO}\end{array}$ & 51.7 & 85.57 & 40.2 \\
\hline $\begin{array}{c}5 \% \\
\mathrm{MCM}-41 / \mathrm{ZnO}\end{array}$ & 71.1 & 21.39 & 42.7 \\
\hline $\begin{array}{c}8 \% \\
\mathrm{MCM}-41 / \mathrm{ZnO}\end{array}$ & 100 & 86.5 & 62.1 \\
\hline
\end{tabular}




\section{Conclusion}

In the present study $\mathrm{ZnO}$ was prepared by precipitation method and modified by MCM-41. The morphology and crystallization of the films as-obtained were characterized by XRD. From the results $\mathrm{The} \mathrm{ZnO}$ nanoparticles were efficiently crystallized in hexagonal phase. The prepared composites powders were used as catalysts to degrade rohdamine B effectively under UV-visable light irradiation.

\section{References}

[1] Arslan, I.A. Balcioglu, T. Tuhkanen, D. Bahnemann, J. Environ. Eng. 126 (2000) 903-911.

[2] T. Robinson, G. Mcmullan, R. Marchant, P. Nigam, Bioresour. Technol. 77 (2001) 247-255.

[3] E. Forgacs, T. Cserhati, G. Oros, Environ. Int. 30 (2004) 953-971.

[4] H.S. Rai, M.S. Bhattacharyya, J. Singh, T.K. Bansal, P. Vats, U.C. Banerjee, Crit. Rev. Environ. Sci. Technol. 35 (2005) 219-238.

[5] V.K. Gupta, Suhas, J. Environ. Manage. 90 (2009) 2313-2342.

[6] J. b. Zhong, J. z. Li, X. y. He, J. Zeng, Y. Lu, W. Hu, K. Lin, Improved photocatalytic performance of Pd-doped ZnO, Current Applied Physics 12 (2012) 998-1001.

[7] Y.W. Chen, Q. Qiao, Y.C. Liu, G.L. Yang, Size-controlled synthesis and optical properties of small-sized ZnO nanorods, J. Phys. Chem. C 113 (2009) 7497-7502.

[8] L. Li, W. Wang, H. Liu, X. Liu, Q. Song, S. Ren, First principles calculations of electronic band structure and optical properties of Cr-doped ZnO, J. Phys. Chem. C 113 (2009) 84608464.

[9] N. Kislov, J. Lahiri, H. Verma, D.Y. Goswami, E. Stefanakos, M. Batzill, Photocatalytic degradation of methyl orange over single crystalline $\mathrm{ZnO}$ : orientation dependence of photoactivity and photostability of ZnO, Langmuir 25 (2009) 3310-3315.

[10] A.M. Ali, Emma A.C. Emanuelsson, D.A. Patterson, Conventional versus lattice photocatalysed reactions: implications of the lattice oxygen participation in the liquid phase photocatalytic oxidation with nanostructured $\mathrm{ZnO}$ thin films on reaction products and mechanism at both $254 \mathrm{~nm}$ and $340 \mathrm{~nm}$, Appl. Catal. B: Environ. 106 (2011) 323-336. 
[11] J. Matos, E.G. López, L. Palmisano, A. García, G. Marcì, Influence of activated carbon in $\mathrm{TiO} 2$ and $\mathrm{ZnO}$ mediated photo-assisted degradation of 2-propanol in gasesolid regime, Appl. Catal. B: Environ. 99 (2010) 170-180.

[12] A. Mills, R. H. Davies and D. Worsley, Water purification by semiconductor photocatalysis, Chem. Soc. Rev., 22, (1993), pp. 417-425.

[13] W. Lowa, V. Boonamnuayvitaya, J. Environ. Management, 127 (2013) 142.

[14] Ch. Reddy, B. Babu, J. Shim, Synthesis, optical properties and efficient photocatalytic activity of $\mathrm{CdO} / \mathrm{ZnO}$ hybrid nanocomposites, Journal of Physics and Chemistry of Solids. 112 (2018) $20-28$

[15] Y. Lu, J. Huang, B. Li, K. Tang, Y. Ma, M. Cao, L. Wang, L. Wang, A boron and gallium co-doped $\mathrm{ZnO}$ intermediate layer for $\mathrm{ZnO} / \mathrm{Si}$ heterojunction diodes, Applied Surface Science. 428 (2018) 61-65

[16] S. Benzitouni, M. Zaabat, M.S. Aida, J. Ebothe, J. Michel, B. Boudine, L. Mansouri, T. Saidani, Morphology and photocatalytic activity of porous (In,Mg) co-doped $\mathrm{ZnO}$ nanoparticles, Optik - International Journal for Light and Electron Optics, 156 (2018) 949-960

[17] L.C. Damonte, G.N. Darriba, M. Rentería, Structural and electronic properties of Al-doped $\mathrm{ZnO}$ semiconductor nanopowders: Interplay between XRD and PALS experiments and firstprinciples/DFT modeling, Journal of Alloys and Compounds, 735 (2018) 2471-2478

[18] A.G. El Hachimi, H. Zaari, M. Hamedoun, A. Benyoussef, A. El Kenz, O. Mounkachi, Experimental and theoretical investigation of $\mathrm{Nd}$ doped $\mathrm{ZnO}$, Journal of Magnetism and Magnetic Materials, 444 (2017) 416-420

[19] N.J. Ridha, M.H.H. Jumali, A.A. Umar, F. Alosfur, Defects-controlled ZnO Nanorods with High Aspect Ratio for Ethanol Detection, Int. J Electrochem. Sci. 8 (2013) 4583

[20] D. Calestani, M. Zha, R. Mosca, A. Zappettini, M.C. Carotta, V.Di Natale, L. Zanotti, Growth of ZnO tetrapods for nanostructure-based gas sensors, Sens. Actuators, B, 144 (2010) $472-478$

[21] A. Goux, T. Pauporté, J. Chivot, D. Lincot, Temperature effects on $\mathrm{ZnO}$ electrodeposition, Electrochim. Acta 50 (2005) 2239-2248.

[22] Shape factor (X-ray diffraction), U.S. Department of Energy, Office of Scientific and Technical Information, available on: 
http://www.osti.gov/engage/rrpedia/Shape_factor_\%28Xray_diffraction\%29\#cite_note-0 (Accessed Jan. 5, 2013).

[23] S. Juneja, A. A. Madhavan, A. Ghosal, R. G. Moulick, J. Bhattacharya, Synthesis of Graphenized Au/ZnO Plasmonic Nanocomposites for Simultaneous Sunlight mediated Photocatalysis and Anti-microbial Activity, Journal of Hazardous Materials, 347 (2018) 378-389.

[24] K. R. Chandrasekhar, S. S. Arbuj, Solvothermal Synthesis of One Dimensional ZnO Nanostructures and Its Photocatalytic Applications, Materials Today, 2 ( 2015 ) 4575 - 4591.

[25] M. Azarang, A. Shuhaimi, R. Yousefi, A. M. Golsheikh, M. Sookhakian, Synthesis and characterization of $\mathrm{ZnO} \mathrm{NPs} /$ reduced graphene oxide nanocomposite prepared in gelatin medium as highly efficient photo-degradation of MB, Ceramics International 40 (2014) $10217-10221$. 